UDK 351.78

https://doi.org/10.18485/fb_ic4hs.2018.12

\title{
PERSONALISED SECURITY: A STEP TOWARDS APPLIED HUMAN SECURITY
}

\author{
Savvas E. CHRYSOULIDIS *, Phaedon KYRIAKIDIS **
}

\begin{abstract}
Human security' as a term was first introduced in the United Nations Human Development Report in $1994^{1}$. The after-effect of the report was the ascertainment that the state's security did not at the same time achieve individual empowerment and security of people residing in its territory. Adjunct to the introduction of the term Human Security was the decisive shift of the centre of gravity in the field of security, from the state (statecentric) to the human (people-centric) ${ }^{2}$. As a result, the subject of human security is the individual people, not the state.

A first important step in this direction is the redetermination of the threats (new and old ones) that contemporary man is facing and managing, both those which emanate from the physical but evenly the human environment.

The purpose of the article is to highlight the use of new technologies to further strengthen human security as they now provide the toolbox to achieve the idealisation and deepening of the human-centred orientation of human security into the personalised security.

Personalised human security refers to the safety that assesses the geospatial characteristics of each person and applies accordingly to these. Each person has a unique geospatial profile (identity) that is spatio-temporal and formed both by the natural environment in which a person operates and interacts, and by the culture that the person advocates taking into account its continuously-changing nature.

From the above, the necessity arises to define the individual elements that compose this geospatial profile. Lastly, people who safeguard security are redefined, including individuals who are given the opportunity to contribute to their security, with a nonpassive stance as it has been so far but active and in cooperation with other players that
\end{abstract}

\footnotetext{
${ }^{*}$ Ph.D. Candidate, Department of Civil Engineering and Geomatics, Cyprus University of Technology (CUT), chrysoulidis@hotmail.com

** Proffesor, PhD, Department of Civil Engineering and Geomatics, Cyprus University of Technology (CUT), phaedon.kyriakidis@cut.ac.cy

${ }^{1}$ (United Nations Development Programme, 1994).

2 ("Human Security in Theory and Practice: An Overview of the Human Security Concept and the United Nations Trust Fund for Human Security," 2009)
} 
play a role. In addition, it is reported that during a threat the management focuses on the person / persons exposed to it and not only the threat.

Keywords: Human Security, geospatial profile, applied human security, personalized security, human security threats

\section{INTRODUCTION}

Humans, similar to animals, are born with inherent instincts, the most important of which is a survival instinct. The definition of the survival instinct is contained in the ability to know what to do to stay alive (2018, Merriam-Webster Dictionary). Contemporary humans belong to organised societies, where roles and responsibilities for human-related issues pertaining to survival and well-being are assigned to a specific group of people. This group of people has strict roles and responsibilities and constitutes the authorities of a state. Of utmost concern is the security of the citizens from all potential threats against humans, an issue that is commonly the state's responsibility around the world. This notion of security is called Human Security (HS) (Kofi Annan, 2001), and is considered as the ultimate form of all kinds of security concerns, as the other forms such as national military security, have the success of HS as their final objective (Lincoln Chen, 1995).

This paper aims to contribute to the enhancement of HS by proposing a framework of increased human security awareness at the individual level, as contemporary humans typically forego their responsibility to protect themselves and hand over this role to state authorities. As state stakeholders do not often use new technologies and their capabilities to customize their services to individual needs and thus often operate inefficiently, this paper advocates the use of modern technologies by state authorities in order to achieve enhanced HS.

This modern approach to HS can only succeed via the exploitation of new technologies, as they produce a multiplier effect on the enhancement of human capabilities and on the mitigation of their vulnerabilities, so that individuals can be protected from critical (severe) and pervasive (widespread) threats and situations (Commission on Human Security, 2003). In this direction, a new term 'geospatial profile' should be introduced for the identification of customised security needs of individuals, which is expected to change the current state of mind in HS in two directions. First, by making individuals aware of threats and how to mitigate their impact on their lives, and second, by providing state authorities with new tools and data in order to offer personalised HS by saving resources and lives. In the long term, the geospatial profile will offer another crucial and essential factor for HS to succeed; namely, the active participation of every individual who can be influenced by a threatening situation, or who can influence this situation by his/her actions. The individual's passive behaviour dramatically reduces the possibilities to act/respond in the most efficient way during a threatening situation and deal with it. As a result, individuals should be repositioned as the main actors to safeguard HS, and their synergy should be counted upon along with all other stakeholders. Moreover, the introduction of a new approach aiming to understand individual behaviour in space and time, to personalise and specify weaknesses and capacities in order to provide the basis to evaluate and manage their participation in different ongoing situations, is considered an 
imperative necessity. The introduction of a notion of geospatial profile is a prerequisite towards clarifying stakeholder relation to human security, as well as the type of securities connecting human security and corresponding threats. In addition, the undermentioned in paragraph 4, the introduction of the new term 'geospatial profile' offered in this paper, furnishes a tool (via the use of modern technologies) for the individuals to make it possible to change their role, to become more actively involved and finally to obtain security mentality.

\section{HUMAN SECURITY STAKEHOLDERS}

Numerous stakeholder theories and definitions (Economie \& Bedrijfskunde, 2008) describe in a holistic way the term HS, as opposed to other terms, such as an actor (actors are always stakeholders but stakeholders are not always actors) or a role player. Primarily the term stakeholder was devised and introduced for organisations management and general business environments, but later was used in other realms, such as security. Edward R. Freeman, who is considered the "father of the stakeholder concept" (Fontaine, 2006) published many definitions, one of which is "Any group of individuals who is affected by or can affect the achievement of an organisation's objectives" [Freeman \& McVea, 2001 (Freeman, 1984, pg. 5)]. This definition could be modified within a HS perspective, to become "any individual, group (made up of people who share a common interest) or organisation which can be influenced by a project or can influence this project", where the term project could pertain to any kind of issue or state.

Within the context of the most widely known theories about stakeholders (Donaldson \& Preston, 2018), it is critical to understand how each stakeholder behaves and to understand his/her actions, roles and responsibilities, as well the ethical principles within the objectives of the organisation the stakeholder belongs to.

\section{Stakeholder mapping}

States around the globe have many differences due to different historical transitions in political, social, environmental, economic, military and cultural systems they operate in. For this reason it is impossible to identify similar (in terms of a name or role) stakeholders for different states. However, an overarching link is the common threats that human citizens of different states must deal with, and on this basis a different approach to emergencies and other security issues should be established using all the existing theoretical backgrounds, to identify the proper stakeholders involved in each different situation, irrespective of the differences between states. This different approach focuses on the security of human life, by monitoring the position of each individual, independently of the kind, of the threatening situation or its evolution. All relevant stakeholders are properly mapped according to how the lives of the individuals are possibly affected due to their position with relation to the threat. For instance, in a fire emergency situation, where one is monitoring the threat (fire), the proper stakeholders are the firefighters, and their role is clearly to extinguish the fire. The case of this fire causing an electricity failure, however, could put traffic lights out of order and thus cause several car accidents, possibly causing deaths that the fire itself would not have caused directly. According to this new approach, 
which calls for monitoring individuals and not the fire (threat) itself, the relevant stakeholders (traffic police, electricity company employees) will be more efficiently involved, focusing on the synergistic monitoring of the position of individuals in connection to the threat, instead of monitoring the threat alone.

Stakeholder mapping can be addressed into two contexts, national and international. In most states, national stakeholders are civilian government agencies (health, transportation, education, and many other agencies), security sector (military, police, firefighters, intelligence services, justice and rule of law institutions), non-state armed groups, business sector, civil society (local religious institutions, local universities, and community-based organisations), media and non-governmental organisations (NGOs). International stakeholders could be international organisations (the UN, the World Bank, the International Monetary Fund), intervening states, contractors ${ }^{3}$, humanitarian organisations (UN humanitarian agencies, the Red Cross/Red Crescent Movement, humanitarian nongovernmental organization), international non-governmental organizations (NGOs) and transnational non-state armed groups (Schirch, Lisa, 2016). The common point for all stakeholder, regardless of states and roles, is the fact that their cornerstone is the human being itself.

\section{Stakeholder roles and responsibilities}

Governments retain the primary role and responsibility for their citizens (United Nations General Assembly, 2012). Stakeholder roles and responsibilities are involved in response to various pressures and influences according to stakeholder behaviours and cultures, as a result of facing multifarious threats caused by a continuously changing complex environment. This implies that stakeholder roles and responsibilities are not static or immutable. New or old threats (with new different impact) demand that we reconsider the roles and responsibilities, such as the involvement of the armed forces to manage additional threats beyond national defence (Krupanski, 2002). The most efficient way to identify primary and secondary stakeholders, in order to organise and share roles (first responders, coordinators) and responsibilities, is to follow a top-to-bottom approach. Threats are placed on the top of the pyramid and stakeholders are placed at the bottom. Secondly, the impact of each stakeholder should be identified in this pyramid, according to their power and capabilities (Mayers, 2005) in each specific moment and situation. Moreover, impact should be classified as positive, negative or neutral. Stakeholder behaviour can be delineated investigating past actions, studying similar situations in order to analyse their actual behaviour and find potential cooperation (Fontaine, 2006). Beside this, a constructive and logical explanation can report on why specific stakeholders act in a particular way. Key stakeholders remain the individuals, as they constitute the core of HS and the cell of each organisation. It is critical to know how they act in emergencies and in other incidents related to their security, by understanding their responsibilities in fulfilling their roles. The empowerment of HS is only possible via the change of individuals'

\footnotetext{
${ }^{3}$ Contractors, also known as private military corporations (PMC), private military firms (PMF), or private military or security companies.
} 
mentality ${ }^{4}$ (Javaid, 2013). In a fire incident, for example, the main difference between firefighters and the individuals who are in danger is the different way of thought (mentality), as firefighters are well trained and prepared, given their role and responsibility, to save people. A person, on the other hand, with no security mentality, acts passively, performing the role of a victim, without feeling any responsibility for the outcome of the ongoing situation, even if this affects his/her own life.

\section{TYPES OF HUMAN SECURITY - THREATS}

The term security was first introduced by Cicero and Lucretius referring to a philosophical and psychological state of mind, or the subjective feeling of freedom from sorrow (UNUEHS, 2005). Nowadays, the term security is more often used in connection with the phenomenon of globalisation (Fukuda-Parr, 2003). Apart from academic research, policymaking stakeholders and organisations related to the security domain also focus on the global dimension of security. This paper aims to make a step forward for human security, by moving away from people-centred HS to personalised HS, and from the global focus to the personal focus, beyond the community or local level. However, the main concept remains the same. The ultimate purpose of human security is the protection and empowerment of individuals from all threats that are beyond their control ${ }^{5}$.

\section{Types/Dimensions of Human Security}

The Human Development Report (HDR) of $1994^{6}$ introduced seven main types/dimensions of security within which threats can be categorized; these are economic, food, health, environmental, personal, community, and political security. However, the question of 'security' was once just a political and social one, but today it is becoming more cultural (Watanabe, 2018). Of course, the concept of culture is not new, but human cultural insecurities ${ }^{7}$ are recently taken into consideration for causing tensions, hostilities and general threats to human beings. Therefore, another type of security should be introduced in order to succeed in integrated management of HS. This type is Cultural Security (Alkire, 2003), the eighth type/dimension of HS. Strong approval of the importance of the cultural dimension of human security is corroborated by the establishment of UNESCO (UNESCO, 1995) and the number of states which recognise and participate in this international organisation under the United Nations.

\section{Human Security threats}

Four security dangers can be distinguished, and these are: threats, challenges, vulnerabilities and risks (Brauch, 2011). Risks are considered as the lowest level of dangers, while threats are the highest. Challenges are the escalation level between threats

${ }^{4}$ The term security introduced by Cicero and Lucretius refers to a philosophical and psychological state of mind, this is the security mentality I referred to, the state of mind.

${ }^{5}$ Ibid. p. 7

${ }^{6}$ Ibid. pp. $24-25$

${ }^{7}$ Ibid. pp. 17-32 
and risks, and vulnerabilities are the weaknesses that expose an organisation to risks. Threats are the last level of security dangers that affect directly human beings' livelihood and empowerment ${ }^{8}$. A list that includes all the threats against human security is almost impossible to be compiled and might be needless. New threats are being continuously recorded as the technological evolution is ongoing. New threats, like cyberattacks, data fraud or theft, climate change and fake news are only some of those ${ }^{9}$. The categorisation of the most widespread and severe threats under the eight types of security mentioned above could be a starting point in order to record the main threats and collect data, and find how individuals can protect and empower themselves. Some of the main threats that can be classified in eight types of security are: economic security (persistent poverty, unemployment), food security (hunger, famine, spoiled food), health security (deadly infectious diseases, unsafe food, malnutrition, lack of access to basic health care), environmental security (climate change, environmental degradation, resource depletion, natural disasters, pollution, water crisis), personal security (physical violence, crime, terrorism, domestic violence, child labour, fake news), community security (inter-ethnic violence, vandalism against public property, civil war), political security (political repression, human rights abuses, corruption incidents, war), cultural security (monuments - heritage disaster, art crimes, racism crimes, violation of cultural rights, religious and other culture-based tensions, genocide based on discriminations). The recording and categorisation of threats in the eight above mentioned types of security can be accomplished via the use of new technologies which are necessary for the implementation of the geospatial profile, details of which will be introduced in the next paragraph. The geospatial profile could provide individuals with the ability to increase their awareness of all potential threats, which, in conjunction with proper awareness of vulnerabilities and strengths, could help protect themselves more effectively and efficiently. The global point of view focuses on transnational threats (Patrick, 2006), such as military conflicts, terrorism and other (Report, 2018). Minor security issues that individuals might have to deal with every day are secondary in importance for governmental authorities, but can have a huge negative impact on the lives of individuals.

\section{GEOSPATIAL PROFILE}

The main difference introduced in this new approach towards HS is the consideration of individuals separately, ensuring a customised (personalised) security, adapted to the personal, unique and dynamic needs of each individual. Until now, stakeholders in the security domain have treated individuals as a common, unified and indivisible whole, often called a society or community. This approach has a negative impact on how people 'perceive' their roles and responsibilities from minor to large-scale security incidents. Moreover, when planning the crisis response and risk management, individuals have a neutral or negative participation, because they are considered, from a policy-making standpoint, more as victims than as equally capable and critical stakeholders. If one takes

\footnotetext{
${ }^{8}$ Ibid. p. 7

${ }^{9}$ Ibid, Figure IV
} 
into consideration that in the majority of incidents (from civil wars and hostilities to a wildfire or car accidents) individuals are by far the greatest part of the people involved, then it can be easily understood how they impact (by their neutral or negative contribution) the evolvement of the incident. Nowadays, new technologies such as Geoinformatics, Spatial Analysis, Geographic Information Systems, Data Science and Analytics provide the required toolbox to identify and analyse/model the characteristics of each individual in order to personalise his/her security. This policy change in the long term will redefine the role of individuals, responsibilities and their security attitude. The final purpose remains their protection and empowerment ${ }^{10}$. In what follows, we will introduce the Geospatial Profile (spatial identity), which refers to the characteristics/elements of each person, based on two pillars comprising the physical (natural) and human environment.

\section{Geospatial profile characteristics/elements}

The elements of the geospatial profile pertaining to the physical environment originate from studies on the vulnerability (Lukacs \& Bhadra, 2012) and capacities (Hansford, Faleiro, Hughes, Marshall, \& Wiggins, 2011) of individuals towards natural hazards (Papathoma-Köhle, Neuhäuser, Ratzinger, Wenzel, \& Dominey-Howes, 2007), other physically-based emergencies and issues relevant to HS. Examples of such physical elements, which influence the way a person or group of people is affected by reducing or increasing the individual's capacities and vulnerabilities are: the precise position of a person - Coordinates, Elevation, Slope, Hydrology of the area, Weather, Land Cover Land Use. Human environment elements arise mainly from the answer to the question: which factors affect the individual's decision-making process, and focus on the behaviour of one person or group of people mainly during crisis situations (Arru, Negre, 2017) and other threatening socio-economic phenomena. Examples of such human environment elements are: Socio-Economic Status (SES) [Age, Sex, Nationality, Religion, Residence Place, Level of Education, Civil Status (married with children, divorced etc.), Income (wealthy, car owner) and Occupation], Health Condition, Government Role (Civilian/Civil Protection/Local or Federal Enforcement/Armed Forces) ${ }^{11}$. The Geospatial Profile is dynamic, because its constituent elements change continuously over time (short and longterm ones). In addition, the Geospatial Profile is person-specific, since its constituent elements are unique for each person; in other words, the geospatial profile is considered as the spatio-temporal 'identity' of each human being. Moreover, under some parameterisation of the constituent elements, the geospatial profile could be used in an aggregate or mean sense to characterise groups of people, organisations, communities, regions and generally defined structures with spatial characteristics. Providing the capability/opportunity to an individual to be aware of his/her geospatial profile (specify vulnerabilities and capabilities), while at the same time becoming responsible for potential dangers (before they become threats), can be considered as a starting point for a person to acquire security mentality. For instance, one could visualise how an individual will act in

\footnotetext{
${ }^{10}$ Ibid, p.7

${ }^{11}$ Ibid, p.48-54
} 
case of a flood, if one knows from his geospatial profile the hydrographic network, land cover, slope in relation to his/her position. On the other hand, this profile is expected to be of significant value to security authorities when they plan and execute their duties, along with elements like individual health condition, age, existence of car or not, or recorded history of similar incidents. Finally, with the implementation of the geospatial profile, the necessary data mentioned above (elements of physical and human environment) are collected from the source (from individuals who are influenced by a threatening situation) and for the first time the data will correspond to each person who has specific and recorded characteristics, solving the lack of observable and structural input data (Douglas, 2007). The timely and accurate data directly acquired from the source are expected to promote the analysis of a threatening situation in an efficient way, providing lessons learned for future exploitation and finally the involvement of all proper stakeholders and the mitigation of the final situation. Moreover, real-time recording of data could provide a useful database for further research on HS.

\section{CONCLUSIONS}

This article proposes ways in which new technologies can provide a framework to make the necessary transition from people-centred to personalised Human Security. It also advocates new roles and responsibilities for individuals in order to implement a new state of individual's mind, as the current state of individuals not acting responsibly (and not knowing what type of action to take) for their own security, is the main reason of the failures in HS, where every failure counts in terms of human lives. Novel approaches are needed to deal with new threats; otherwise, the repetition of previous failures is inevitable. A wide variation of HS definitions and approaches creates a question about whether the concept of human security can serve as a practical guide for academic research or governmental policy-making (Barnett et al., 2001). Applied HS can act as a bridge connecting the academic research with policy-making actors in the field. In this direction, as mentioned in the title of this paper, the geospatial profile provides the very first step towards personalised security and towards extending applied HS.

\section{REFERENCES}

Alkire, S. (2003). A Conceptual Framework for Human Security . CRISE Working Paper, $2,53$.

Barnett, M., Beer, F., Brooks, S., Chan, S., Ciof, C., Drezner, D., Weiss, T. (2001). Human Security Roland Paris Paradigm Shift or Hot Air. International Security, 26(2), 87-102. https://doi.org/10.1016/S0140-6736(11)61148-3

Brauch, H. G. (2011). Security Threat, Challenges, Vulnerability and Risks. Coping with Global Environmental Change, Disasters and Security, 5, 61-106.

Commission on Human Security. (2003). Human Security Now. https://doi.org/0-97411080-9

Donaldson T. and Lee E. Preston. (Jan, 1995) The Stakeholder Theory of the Corporation: Concepts, Evidence, and Implications Source. Published by: Academy of 
Management Stable URL: http://www.jstor.org/stable/258887 Accessed: 14-072018 15:31 UTC, Vol. 20, No. 1 (), pp. 65-91

Douglas, J. (2007). Physical vulnerability modelling in natural hazard risk assessment. Natural Hazards and Earth System Sciences, 7(2), 283-288. https://doi.org/10.5194/nhess-7-283-2007

Economie, F., \& Bedrijfskunde, E. N. (2008). Working Paper the Stakeholder Model Refined. Journal of Business, 1-46.

Fontaine, C. (2006). The Stakeholder Theory. Management, 1(December), 37-44. https://doi.org/10.1057/9780230524224

Freeman, E., \& McVea, J. (2001). A Stakeholder Approach to Strategic Management. SSRN Electronic Journal, 1(01), 276. https://doi.org/10.2139/ssrn.263511

Fukuda-Parr, S. (2003). New Threats to Human Security in the Era of Globalization. Journal of Human Development, 4(2), 167-179. https://doi.org/10.1080/1464988032000087523

Hans - Gunter B., UNU Institute for Environment and Human Security (UNU-EHS), Threats, Challenges, Vulnerabilities and Risks in Environmental and Human Security, (2005), p. 7.

Hansford, B., Faleiro, J., Hughes, D., Marshall, M., \& Wiggins, M. (2011). Reducing risk of disaster in our community (Roots 9), 1-100.

Human Security in Theory and Practice: An Overview of the Human Security Concept and the United Nations Trust Fund for Human Security. (2009). Un, 1-45.

Javaid, M. A. (2013). The Psychology of Security. SSRN Electronic Journal, 50-79. https://doi.org/10.2139/ssrn.2342620

Kofi Annan. (2001). Definitions of Human Security - Millenium Report. Global Development Research Centre -, 1-10. Retrieved from http://www.gdrc.org/sustdev/husec/Definitions.pdf

Krupanski, A. S. ; M. (2002). Mapping Evolving Internal Roles of the Armed Forces Mapping Evolving Internal Roles of the. The Geneva Centre for the Democratic Control of Armed Forces, (ISBN 978 - 92 - 9222 - 228 - 4).

Lukacs, M., \& Bhadra, D. (2012). Table of of contents. Schriften Des Forschungszentrum Jlich Reihe Energietechnik, 21(November), 39.

https://doi.org/10.1002/ejoc.201200111

Maude Arru, Elsa Negre. People behaviors in crisis situations : Three modeling propositions. 14th International Conference on Information Systems for Crisis Response and Management (ISCRAM 2017), May 2017, Albi, France. Proceedings ISCRAM 2017 : Agility is coming; 14th International Conference on Information Systems for Crisis Response And Management, pp.139-149, 2017. $<$ hal- 01729057>

Mayers, J. (2005). Stakeholder power analysis. Focus, (March), 24. Retrieved from http://www.policypowertools.org/Tools/Understanding/docs/stakeholder_power_tool_english.pdf 
Papathoma-Köhle, M., Neuhäuser, B., Ratzinger, K., Wenzel, H., \& Dominey-Howes, D. (2007). Elements at risk as a framework for assessing the vulnerability of communities to landslides. Natural Hazards and Earth System Science, 7(6), 765779. https://doi.org/10.5194/nhess-7-765-2007

Patrick, S. (2006). Weak States and Global Threats: Assessing Evidence of "Spillovers." International Relations, (73), 1-31. https://doi.org/10.1162/wash.2006.29.2.27

World Economic Forum Report $13^{\text {th }}$ Edition. (2018). Global Risk Report. Retrieved from http://www.mmc.com/content/dam/mmc-web/Global-Risk-Center/Files/theglobal-risks-report-2018.pdf

Schirch, Lisa (editor). Handbook on Human Security: A Civil-Military-Police Curriculum. The Hague, The Netherlands: Alliance for Peacebuilding, GPPAC, Kroc Institute, March 2016.

UNESCO. (1995). Unesco 1945-1995: A Fact Sheet, 1-8. Retrieved from http://unesdoc.unesco.org/images/0010/001011/101118eo.pdf

United Nations Development Programme. (1994). Human Development Report 1994. Human Development Report, 226. https://doi.org/http://hdr.undp.org/sites/default/files/reports/255/hdr_1994_en_co mplete_nostats.pdf

United Nations General Assembly. (2012). a/66/290, (October), 1-2.

Watanabe, Y. (Eds.). (2018). Handbook of Cultural Security. Cheltenham, UK: Edward Elgar Publishing. doi: https://doi.org/10.4337/9781786437747 